\title{
Ziyang Wei
}

\section{Teuflische Synergie}

\section{Das Faustbuch (1587) zwischen Determinismus und Willensfreiheit}

Die Historia von D. Johann Fausten - auch ,Faustbuch‘ genannt, 1587 anonym erschienen und als Ursprung der Fausttradition angesehen - erzählt von dem Leben der Titelfigur, eines Magiers des turbulenten sechzehnten Jahrhunderts, sowie von seinem Teufelsbündnis, seinen Abenteuern und seiner ,verdienten“ Verdammung. ${ }^{1}$ Die Teufelsfigur ,Mephostophiles‘ spielt hier - bei ihrem ersten Auftritt in der Literaturlandschaft - schon eine bedeutende Rolle. Dem Teufelsglauben dieser Zeit entsprechend wirkt der Teufel hier weder als schlichte Verkörperung eines abstrakten Prinzips des Bösen noch als Veräußerung des ,inneren“ Faust, sondern als reale Gestalt, die handelt, redet und Faust am Ende tatsächlich körperlich zermalmt.

Die Erzählung vom Teufelsbündler im Faustbuch scheint dabei anders zu funktionieren, als dies in seinen Prätexten, den mittelalterlichen Paktlegenden (z. B. von Theophilus oder Cyprianus), der Fall ist. Diese beruhen in ihrer Darstellung des Verhältnisses zwischen Mensch, Teufel und Gott überwiegend auf einer synergistischen Weltanschauung. Da kann der Mensch sich für das Böse oder für das Gute entscheiden. Selbst nachdem er mit dem Teufel einen Pakt geschlossen und damit die Sünde der Zauberei begangen hat, verfügt er noch über die Möglichkeit, sich entweder durch Reue, durch ein geöffnetes geistiges Auge, mit dem er die göttliche Wahrheit besser sieht, oder durch eine erbauliche Erkenntnis zu bekehren. Doch wenn der Gesinnungswandel sowie die willentliche Entscheidung des Menschen gegen das Böse allein nicht genügen, benötigt der reuige Teufelsbündler zusätzlich den Beistand einer oder eines

1 Textausgabe: Historia von D. Johann Fausten. Hrsg. von Stephan FÜsSEL/Hans Joachim KREUTZER, Stuttgart 2006. Titelblatt: Historia von D. Johann Fausten / dem weitbeschreyten Zauberer vnnd Schwartzkuenstler / Wie er sich gegen dem Teuffel auff eine benandte zeit verschrieben / Was er hierzwischen fuer seltzame Abentheuwer gesehen / selbs angerichtet vnd getrieben / biß er endtlich seinen wol verdienten Lohn empfangen. Mehrertheils auß seinen eygenen hinderlassenen Schrifften / allen hochtragenden / fuerwitzigen vnd Gottlosen Menschen zum schrecklichen Beyspiel / abscheuwlichen Exempel / vnd treuwhertziger Warnung zusammen gezogen / vnd in den Druck verfertiget.

Ziyang Wei, Freie Universität Berlin, Friedrich Schlegel Graduiertenschule, Habelschwerdter Allee 45, 14195 Berlin, ziyang.wei@live.com

Ә Open Access. () 2021 Ziyang Wei, publiziert von De Gruyter. (c) BY-NC-ND Dieses Werk ist lizensiert unter einer Creative Commons Namensnennung - Nicht-kommerziell - Keine Bearbeitung 4.0 International Lizenz. https://doi.org/10.1515/9783110667189-007 
Heiligen; erst mit Hilfe des Vermittlers der göttlichen Gnade wird das Böse überwunden, die begangene Sünde vergeben und der Sünder gerettet. ${ }^{2}$

Faust hingegen wird verdammt und nicht erlöst. Der Roman bietet in seiner Vorred das Argument an, in der Zauberei die schlimmstmögliche aller Sünden zu sehen, so dass die Verdammnis gerechtfertigt sei. ${ }^{3}$ Aber allein die Sünde der Zauberei hebt Faust von seinen Vorläufern nicht ab. So scheint fraglich, was er sich eigentlich zu Schulden hat kommen lassen, um eine unwiderrufliche Verdammnis auszulösen. Auch die bisherige Forschung hat sich wiederholt mit der Frage nach Fausts Schuld auseinandergesetzt. Einerseits hat dies zu Versuchen geführt, verschiedene Verfehlungen des Protagonisten (z. B. seine Verstocktheit, seinen Stolz, die Identifikation mit dem Teufel, seine desperatio) ausfindig zu machen, wie sie Barbara KÖNNEKER in ihrer Studie zu „Faust-Konzeption und Teufelspakt“ auflistet. ${ }^{4}$ Andererseits wurde herausgearbeitet, dass in der Faustfigur und ihrem Handeln eigentlich nichts abgrundtief Böses zu finden sei, sein

2 Vgl. die Paktlegenden in: De Voragine, Jacobus: Legenda aurea. Hrsg. von Marc-Aeilko ARIS u. a., Freiburg i. Br. 2014. Die Erzählung von Theophilus findet sich in ,Geburt der heiligen Jungfrau Maria', S. 1752-1755; die Erzählung von dem Diener von Helladius in der Vita des heiligen Basilius, S. 418-423; die Erzählung von Justina und Cyprianus, S. 1854-1863. Über die Bestimmung des Kriteriums ,Paktlegende، siehe: HAUG, Walter: Der Teufelspakt vor Goethe oder Wie der Umgang mit dem Bösen als felix culpa zu Beginn der Neuzeit in die Krise gerät. In: Die Wahrheit der Fiktion. Studien zur weltlichen und geistlichen Literatur des Mittelalters und der frühen Neuzeit. Hrsg. von DEMS., Tübingen 2003, S. 88-112, hier S. 90-91. In seinem Vergleich zwischen dieser alten Tradition und dem Faustbuch beschränkt HAUG die Diskussion auf den Typ, in dem sich eine menschliche Figur und der Teufel gegenseitig mit einem Pakt verpflichten und die menschliche Seele als Preis eingesetzt wird.

3 Historia, S. 8-9, besonders S. 8: Ohn allen zweiffel aber ist die Zauberey vnd Schwartzkuenstlerey die groeste vnnd schwereste Suende fuer Gott vnd fuer aller Welt. Eine einleuchtende Analyse der Vorrede im Licht der Rhetorik bietet ROLOFF, Hans-Gert: ARTES ET DOCTRINA. Struktur und Intention des Faust-Buchs von 1587. In: Kleine Schriften zur Literatur des 16. Jahrhunderts. Festgabe zum 70. Geburtstag. Hrsg. von Christiane CAEMMERER u. a., Amsterdam u. a. 2003, S. 71-98, hier S. 81-83.

4 Vgl. z. B. KÖNNEKER, Barbara: Faust-Konzeption und Teufelspakt im Volksbuch von 1587. In: Festschrift Gottfried Weber. Hrsg. von Heinz Otto BuRGER/Klaus von SEE, Bad Homburg 1967 (Frankfurter Beiträge zur Germanistik 1), S. 159-213. KöNNEKER weist darauf hin, Fausts Stolz auf sich selbst und die Verzweiflung über seine Rettungsmöglichkeit seien nur zwei Seiten derselben Leugnung der Allmacht Gottes - einerseits die Leugnung der Allmacht von Gottes Herrschaftsgewalt, andererseits die Leugnung von Gottes Barmherzigkeit, und das sei die einzige Sünde, die nicht vergeben werden könne. Neben dieser Hauptsünde werden noch einige Faktoren genannt, die ihn an Besserung hindern: seine Verstocktheit, seine Selbst-Identifizierung mit dem Teufel, die Überschreitung der Grenze der Vernunft wie die Spekulation im Bereich des Glaubens (Luthers radikale Trennung von Vernunft und Glauben vorausgesetzt), und nicht zuletzt die Verführung des Teufels. 
Ende demnach nicht hinreichend motiviert scheine. ${ }^{5}$ Ob Fausts Schuld nun in einer spezifischen Verfehlung erkannt oder ihm generell abgesprochen wird alle Angebote von Antworten auf die Schuld-Frage gehen von folgenden Prämissen aus, denen ein synergistisches Weltverständnis $\mathrm{zu}$ unterliegen scheint: a) diesseitiges Handeln wirkt auf jenseitiges Heil; b) Fausts Verdammung beruht auf einer bestimmten Sünde, die von ihm begangen wird; c) es wäre für Faust möglich gewesen, die Verdammung durch sein Werk, seine Reue oder durch den Glauben zu vermeiden.

Im sechzehnten Jahrhundert aber stand die Idee des Synergismus in starker Konkurrenz zum lutherischen Determinismus. Zwischen 1524 und 1527 entspann sich eine regelrechte Determinismusdebatte zwischen Erasmus und Luther: Der eine verteidigt die Wechselwirkung zwischen Gott und den Menschen, der andere dagegen Gottes Alleinwirkung; der eine vertritt ein neutrales Konzept des menschlichen Willens, der andere dagegen ein negatives; der eine gesteht einen Raum für menschliche Willensfreiheit zu, der andere dagegen keinen. ${ }^{6}$ Luther erkennt dabei die Härte seiner deterministischen Erlösungslehre für die Verdammten und malt ihre absolute Hoffnungslosigkeit wie folgt aus:

\begin{abstract}
Vielleicht aber versetzt das in Unruhe, dass es schwierig ist, die Güte und Gerechtigkeit Gottes zu verteidigen, der doch die verdammt, die es nicht verdient haben; das heißt, derartige Gottlose, die, in Gottlosigkeit geboren, sich in keiner Weise helfen können, nicht gottlos zu sein, zu bleiben und [als solche] verdammt zu werden, die gezwungen sind durch die Notwendigkeit der Natur zu sündigen und zugrunde zu gehen. ${ }^{7}$
\end{abstract}

5 Vgl. Haug, Der Teufelspakt, S. 101f. (Anm. 2); MÜNKLER, Marina: Sündhaftigkeit als Generator von Individualität. Zu den Transformationen legendarischen Erzählens in der Historia von D. Johann Fausten und den Faustbüchern des 16. und 17. Jahrhunderts. In: Literarische und religiöse Kommunikation in Mittelalter und Früher Neuzeit. Hrsg. von Peter STROHSCHNEIDER, Berlin, New York 2009, S. 25-61, hier S. $30 \mathrm{ff}$.

6 Erasmus veröffentlichte 1524 das knapp verfasste De libero arbitrio auf langes Drängen vieler Zeitgenossen als Reaktion auf die protestantische Position über die Frage der Willensfreiheit, vor allem auf Luthers Assertio (1520). 1525 schlug Luther mit dem ungefähr viermal so umfangreichen De servo arbitrio zurück. Sehr schnell darauf im Jahr 1526 veröffentliche Erasmus den ersten Teil der Hyperaspistes, im Jahr 1527 den zweiten Teil. Eine schriftliche Widerlegung von Luthers Seite ist nicht mehr zustande gekommen. Vgl. folgende Editionen: Erasmus von Rotterdam: De libero arbitrio. In: Ausgewählte Schriften, Bd. 4. Hrsg. von Werner WelziG, Darmstadt 1969, S. 1-195. Der deutsche Text in dieser Ausgabe wird von Winfried Lesowsky aus dem lateinischen Original übersetzt. Luther, Martin: De servo arbitrio. In: Lateinisch-Deutsche Studienausgabe. Hrsg. von Wilfred HÄrLE/Johannes SchILLING/Günther WARTENBERG, Bd. 1, Leipzig 2006, S. 219-661. Der deutsche Text in dieser Ausgabe wird von Athina Lexutt aus dem lateinischen Original übersetzt.

7 Luther, De servo arbitrio, S. 650/651. 
Obwohl das Faustbuch mehr als sechzig Jahre später erschien als dieses Porträt der Verdammten, scheint die absolute Hoffnungslosigkeit, die Luther hier prägnant bezeichnet, eine Folie zur Interpretation der Faustfigur und ihrer Schuld zu liefern, wie sie von der Forschung bisher wenig beachtet wurde. Es gilt, nicht zuerst zu fragen, welche Sünde Faust zur Verdammnis führt, sondern zu überlegen, ob der Analyse des Faustbuchs ein Determinismus- oder ein Synergismusgedanke - oder beides - zugrunde liegt. Gewiss, ob die Welt im Faustbuch deterministisch oder synergistisch ist, ist eine transzendente Frage, über die der Leser wie auch der Erzähler selbst nur spekulieren kann. Möglich ist es allerdings zu analysieren, was der Autor zum Vorschein bringt. Im Folgenden werde ich zeigen, wie der Determinismus und die Willensfreiheit im Faustbuch immer wieder neu in ein Spannungsverhältnis treten, und wie dieses Spannungsverhältnis schließlich die Form einer unheilvollen Synergie zwischen dem Teufel und seinem menschlichen Paktpartner annimmt. Wichtig ist zunächst auf der Erzählerebene zu prüfen, ob und inwieweit solch eine deterministische Sichtweise - der Protagonist ist von Geburt an zur Verdammnis prädestiniert - im Faustbuch geltend gemacht wird. Danach wird auf der Figurenebene betrachtet, wie sich die Notwendigkeit (das ,Müssen`), die Möglichkeit (das ,Können`) und der Wille (das ,Wollen`) in der Pakt-Partnerschaft zwischen Faust und Mephostophiles zueinander verhalten. Schließlich werde ich die Besonderheit an der Erzählweise des Faustbuchs hervorheben und auf die Gefahren, zu denen diese führen kann, hindeuten.

\section{Die Erzählerebene}

Die Vorrede des Faustbuchs vermittelt zunächst den Eindruck, dass es eine Möglichkeit der Rettung geben muss, indem hier paränetische und appellative Sprechweisen eingesetzt werden. Explizit zitiert die Vorrede die Bibelstelle Jacob. 4. Seit Gott vnterthaenig / widerstehet dem Teuffel / so fleuhet er von euch / naehet euch zu Gott / so naehet er sich zu euch. ${ }^{8}$ Diese Stelle bestätigt mit Klarheit die Wechselwirkung zwischen Mensch und Gott sowie zwischen Mensch und Teufel, so dass der Mensch doch irgendetwas tun kann.

Im Kapitel 1 dann gibt der Erzähler seine eigene deterministische Neigung zu erkennen. Er erzählt, dass Faust sowohl ein[en] gantz gelernigen vnd geschwinden Kopff[], als auch einen thummen / vnsinnigen vnnd hoffertigen Kopff hatte. Er deutet an, dass Faust seine hervorragende Intelligenz, die im zuerst

8 Historia, S. 12. 
genannten gelernigen vnd geschwinden Kopff[] deutlich wird, ,dummerweise‘ in eine falsche Richtung treibt, so dass man jn denn allezeit den Speculierer genennet hat. ${ }^{9}$ Zählt zu Fausts göttlich gegebener Natur folglich ein thummer Kopf, kann er - nach Luthers deterministischer Überzeugung - keinen guten Willen haben, demzufolge gar nicht anders als sündigen und muss somit seinem Ende in Verdammnis entgegenstreben. ${ }^{10}$ Dass er zur boesen Gesellschafft gerahten ist, dass er die H. Schrifft ein weil hinder die Thuer vnnd vnter die Banck gelegt / ruch vnd Gottloß gelebt hat, scheinen Beweise für die Schlechtigkeit seines Willens zu sein. Darauffolgend wird subsumiert: Aber es ist ein wahr Sprichwort: Was zum Teuffel wil / das laeßt sich nicht auffhalten / noch jm wehren. ${ }^{11}$ Damit wird eine Trias von Fausts thummem Kopf als Teil seiner Natur, seinem schlechten Willen und seiner Verdammnis hergestellt. Es ist nicht mehr die Entscheidung zur Sünde, die zur Verdammnis führt, sondern eigentlich ist die unausweichliche Art und Weise, wie die Sünde aufgrund von Fausts Natur und durch seinen Willen hervortritt, bereits durch die Prädestination Gottes vorherbestimmt.

Obwohl der Erzähler seinen Protagonisten schon in früheren Phasen mehrmals verdammt - einmal im allgemeinen Sinne der Prädestination, zweimal wegen konkreter Taten -, muss er sich immer noch mit der Frage auseinandersetzen, ob Faust überhaupt durch Reue seine Sünde büßen und sich retten kann. ${ }^{12}$ Dies bildet - wie wir sehen werden - ein zentrales Spannungsfeld in der Erzählung. Der Erzähler schildert kommentierend, dass Faust zwar Ansätze von Reue zeigt, jedoch nicht richtig bereuen könne; er verzweifelt vielmehr nur:

Doctor Faustus hatte wol jmmerdar eine Rew im Hertzen / [ . . ] Aber sein Rew war Cains vnnd Jude Reuw vnd Buß / [. . .] er verzagte an der Gnade Gottes / vnnd war jm ein vnmoeglich Ding / daß er wider zur Hulde GOttes kuendte kommen. Gleich wie Cain / der

9 Ich berufe mich auf KÖNNEKER: Dieses thumm bedeutet „religiöse Unerleuchtetheit und Gottesblindheit, weist also hin auf jenes Phänomen der Verstocktheit, von dem in der Vorrede im Hinblick auf Faust schon die Rede war." KöNNEKER, Faust-Konzeption, S. 175/176 (Anm. 4).

$10 \mathrm{Vgl}$. MÜlLER, Maria E.: Der andere Faust. Melancholie und Individualität in der Historia von D. Johann Fausten. In: DVjS 60/4 (1986), S. 572-608, hier S. 580 f. MÜLLER weist auf die Bipolarität des melancholischen Gemüts hin. Aufgrund dessen ist auch zu schließen, dass beide der Köpfe zur Natur Fausts gehören.

11 Historia, S. 14.

12 Zweimal Verdammung wegen konkreter Taten: das erste Mal nach der Tat, als Faust Mephostophiles nach seinem Namen fragt (siehe Historia, S. 21: Eben in dieser Stundt), und das zweite Mal nach dem Zustandekommen des Pakts (siehe Historia, S. 26). Es ist in doppelter Hinsicht merkwürdig: Einerseits wird hier ein Mensch mehrmals verdammt, andererseits beginnt die Spannung, ob sich Faust überhaupt retten kann, erst nach der Verdammung. 
also verzweiffelte / Seine Suende weren groesser / denn daß sie jhme verziehen moechten werden / Also auch mit Judas, etc. ${ }^{13}$

Der Erzähler markiert Fausts Reue als Cains vnnd Jude Reuw. Auf ähnliche Weise wird das folgende Selbstbekenntnis Fausts in seiner letzten Rede an seine Studenten durch eine Marginalie als Judas Rew denunziert:

Dann ich sterbe als ein boeser vnnd guter Christ / ein guter Christ / darumb daß ich eine hertzliche Reuwe habe / vnd im Hertzen jmmer vmb Gnade bitte / damit meine Seele errettet moechte werden / Ein boeser Christ / daß ich weiß / daß der Teuffel den Leib wil haben / vnnd ich wil jhme den gerne lassen / er laß mir aber nur die Seele zu frieden. ${ }^{14}$

Mit dem Exempel von Judas möchte der Erzähler zeigen, dass Faust keine echte Reue haben und seine Verdammnis nicht umgehen kann. ${ }^{15}$ Das klingt deterministisch - um Gottes Plans willen muss Judas regelrecht verdammt werden. Aber zugleich darf der synergistische Ton im Judas-Exempel nicht überhört werden. Judas' eigentliche Verfehlung soll in seiner Verzweiflung an Gottes Gnade liegen. Der Erzähler deutet dementsprechend auf die Möglichkeit an, ,wider' zur Hulde GOttes kommen zu können, wenn Faust nicht verzagt wäre. Er schildert im Kapitel 14 sogar mit einer Ich-Stimme exemplarisch, wie Faust hätte büßen können:

Denn wenn er gedacht hette: Nun streicht mir der Teuffel jetzt eine solche Farbe an / daß ich darauff muß in Himmel sehen / Nun so wil ich wider vmbkehren / vnd Gott vmb Gnade vnd Verzeihung anruffen / Denn nimmer thun / ist ein grosse Buß / hette sich darauff in der Christlichen Gemein in die Kirchen verfuegt / vnnd der heyligen Lehre gefolget / dardurch also dem Teuffel eine widerstand gethan / ob er jm schon den Leib hie hette lassen muessen / so were dennoch die Seele noch erhalten worden [. . . $]^{16}$

Dieser Bußspiegel hebt sich als eine bessere Sprechweise dadurch hervor, dass er sich an eine Klage Fausts anschließt, die als Fausts Verzweiflung gelesen werden soll. Man merkt aber, dass der Gedanke - den Leib hie hette lassen muessen / [ . . ] dennoch die Seele noch erhalten - fast in gleicher Form erscheint wie Fausts spekulatives Kalkül in seiner letzten Rede: [. . .] daß der Teuffel den

\footnotetext{
13 Historia, S. 36.
}

14 Historia, S. 121.

15 Judas ist ein klassisches Motiv, das die theologische Überlegung um die Verhältnisse zwischen Gut und Böse, zwischen Gottes Prädestination und menschlich-freiem Willen anregt. Vgl. OHLY, Friedrich: Der Verfluchte und der Erwählte. Vom Leben mit der Schuld, Opladen 1976. Erasmus und Luther greifen ebenfalls auf das Judas-Motiv zurück, wenn auch mit unterschiedlichen Schwerpunkten. Vgl. Erasmus, De libero arbitrio, S. 102-105; Luther, De servo arbitrio, S. 490-495.

16 Historia, S. 33. 
Leib wil haben / vnnd ich wil jhme den gerne lassen / er laß mir aber nur die Seele zu frieden. ${ }^{17}$ Ein merkwürdiges Phänomen: Der Gedanke, wenn er vom Erzähler formuliert ist, gilt als heilsam; aber wenn Faust mit demselben rechnet, gilt er nun als Judas Rew. ${ }^{18}$

Fausts Konzeption als negativ-exemplarische Figur ist relativ eindeutig. Aber die Art und Weise, wie der Autor diese Konzeption realisiert, ist theologisch-philosophisch nicht immer kongruent. Maria E. MÜLLER weist darauf hin, dass das Faustbuch als Negativ-Exempel solch eine zentrale Antinomie beinhaltet:

Abschreckend vermag das Exempel nur zu sein, wenn es das furchtbare Ende des gottlosen Faust als notwendige Konsequenz seines Strebens glaubhaft machen kann. Um aber lehrreich zu sein, müssen die Sünden und Laster der Exempelfigur für die Rezipienten vermeidbar erscheinen. ${ }^{19}$

Bezieht man die deterministische Perspektive in das Faustbuch ein, so konstituiert diese auch eine Antinomie: Die Erzähllogik des Negativ-Exempels schließt die Möglichkeit der Rettung für Faust aus und ,prädestiniert' ihn zur Verdammnis; aber indem er genau als Exempel dienen soll, kalkuliert der Text doch auf mit möglichen Rettung, wenn man sich denn nur richtig verhalten hätte - dieses Verhalten kann keine Folge von Prädestination sein, weil der Text selbst dann nicht nötig wäre bzw. die paränetische Rahmung sich selbst unterliefe. Aufgrund dieser konzeptionellen Schwierigkeit bekennt sich der Autor theologisch nicht eindeutig - weder zum Determinismus, noch zur Synergie.

Er zeigt sich deterministisch gesinnt, wenn er die Faust-Figur als Verdammten einführt und auf die Unausweichlichkeit der Verdammnis hindeutet. Er schreibt ihm zwar einen Raum des Willens zu, entzieht ihm aber die Möglichkeit, diesen Willen in eine andere Richtung zu orientieren. Andererseits zeigt sich der Autor synergistisch gesinnt, wenn das Bedürfnis entsteht, aus der Erzählung eine Didaxe oder Paränese zu machen, oder wenn die lutherische Härte gegenüber dem Verdammten gespürt wird. Hinter der Verbindung zwi-

17 Historia, S. 121.

18 Inmitten der theologischen Konfusion profiliert sich der Autor als oberster Richter, der Urteile über Recht und Unrecht bzw. Gerechtigkeit und Sündhaftigkeit fällt, was aber eigentlich nur Gott zukommen sollte. Vgl. MüNKLER, Marina: Narrative Ambiguität. Die Faustbücher des 16. bis 18. Jahrhunderts, Göttingen 2011 (Historische Semantik 15), S. 69. Diese selbstberechtigende Vorgehensweise des Autors steht in einem gespannten Verhältnis zu der religiösen Demut, relativiert auch die Überzeugungskraft seiner Kommentare über Faust - insbesondere die Bemühung, in Faust Stoltz vnnd Hochmut (siehe z. B. Historia, S. 21) seine Verfehlung zu identifizieren.

19 MÜLlER, Der andere Faust, S. 573 (Anm. 10). 
schen konkreten Akten und Strafe, zwischen Reue und möglicher Rettung steht die synergistische ,Tun-Verdienst'-Logik, die entweder warnend oder belehrend wirkt. Die Modifikation zwischen den theologisch-philosophischen Grundtönen stiftet Sinn im jeweiligen textimmanenten Zusammenhang wie auch auf der Ebene der literarischen Bearbeitung.

Allein der Fakt, dass sich Faust nicht gerettet hat, führt nicht notwendig zu dem Schluss, dass er sich wegen Gottes Prädestination nicht hat retten können. Ebenfalls stellt das Faustbuch keinen ausreichenden Beweis für eine synergistische Erklärung seiner Verdammnis zur Verfügung. Anders verhält es sich z. B. im Jesuitendrama Cenodoxus von Jakob Bidermann (Uraufführung 1602), in dem der explizite Zusammenhang zwischen Sünde und daraus resultierender Strafe eine synergistische Weltanschauung suggeriert: Der Protagonist muss sich immer zwischen Gut und Böse entscheiden, nach seinem Tod vor dem überirdischen Gericht stehen und schließlich wegen seiner Sünden das Urteil von Christus erhalten. ${ }^{20}$

Die unverkennbare theologisch-philosophische Inkongruenz innerhalb des ganzen Faustbuchs ist ein Indiz der intellektuellen Krise des Jahrhunderts. Suggeriert es eine Form von Hochmut, wenn die Ursache der Verdammnis eines Menschen synergistisch in seinen Taten gesehen wird, was suggeriert es dann, wenn diese Ursache deterministisch schließlich in Gottes Prädestination gesehen wird? ${ }^{21}$ Luther würde sich an die letztere Sichtweise anschließen, obwohl er auch von der absoluten Hoffnungslosigkeit der Verdammten beeindruckt ist und in dieser Hinsicht findet, „dass es schwierig ist, die Güte und Gerechtigkeit Gottes zu verteidigen“. ${ }^{22}$

\section{Die Figurenebene}

Was der Teufel treibt, ist in einer komplexen Weise mit Gottes Willen verbunden. Er ist entweder Vollstrecker vom Willen Gottes oder, worauf die typische Betrachtungsweise der Reformationszeit hindeutet, Gottes mächtiger Widersacher.

20 Bidermann, Jakob: Cenodoxus. Hrsg. von Rolf TAROT, Stuttgart 2012.

21 Über die historische Möglichkeit dieser Sichtweise vgl. MÜLLER, Der andere Faust, S. 585-586 (Anm. 10): „Ob die Melancholie Fausts als Folge selbst verschuldeter Sünde oder als Folge schwerer, womöglich von Gott verfügter und jedenfalls von Gott zugelassener Krankheit aufzufassen sei - bei Strafe des Todes darf dies kein Gelehrter im späten 16. Jahrhundert diskutieren. Die wissenschaftlich bedeutenden zeitgenössischen Theorien aber lassen beide Möglichkeiten zu.“

22 Luther, De servo arbitrio, S. 650/651. 
Im Folgenden geht es hauptsächlich um das Duo Faust und Mephostophiles. Ich werde chronologisch die verschiedenen Phasen ihrer Beziehung durchgehen, um schließlich die auf- und absteigenden Entwicklungen der Willensfreiheit Fausts und seiner Selbstständigkeit in der Pakt-Partnerschaft verzeichnen $\mathrm{zu}$ können. Es ist durchaus berechtigt, wie es die bisherige Forschung getan hat, den Schwerpunkt der Analyse auf Mephostophiles' Macht über Faust und Fausts Abhängigkeit zu legen. Doch wird dieses Verständnis der Beziehung zwischen den beiden Akteuren der Spezifik der Konstellation nicht gerecht. Im Faustbuch ermöglicht einerseits der Teufelspakt Faust vieles. Andererseits ist Mephostophiles ein konkreter, menschenähnlicher Akteur, der mit Faust redet und handelt, der Faust berät und ihm hilft, seine Zaubereien $\mathrm{zu}$ realisieren, nicht etwa eine schlichte Chiffre der unausweichlichen universellen Sündenverfallenheit. Der Teufel braucht - wie die Dämonologie des Mittelalters und der Frühen Neuzeit nahelegt - auch unbedingt die Allianz mit dem Menschen. ${ }^{23}$ Deshalb ist die Ungleichheit in den Machtverhältnissen zwischen Faust und Mephostophiles nicht zu überschätzen. Ich werde die Beziehung zwischen den beiden Figuren konkret in ihrer Pakt-Partnerschaft betrachten und zeigen, dass der Machtkampf zwischen ihnen allmählich in eine Beziehung mündet, die ähnlich wie die Partnerschaft zwischen Gott und Christ des synergistischen Modells erscheint.

\subsection{Die Stationen zum Teufelspakt: Fausts Willensstärke}

Faust speculiert vnd studiert Nacht vnd Tag in den Zauberbüchern. Sein Datum stellte sich wie folgt dar: [D] as zulieben / das nicht zu lieben war / dem trachtet

23 Bei Augustinus hatte der Teufel einen Luftkörper, seit dem 12. Jahrhundert aber setzten die Scholastiker die Idee der Unkörperlichkeit des Teufels langsam durch. Man hat dauerhaft die Schwierigkeit empfunden zu erklären, wie ein luftiges oder geistiges Wesen materiellen Schaden anzurichten vermag. Es wurde z. B. von Thomas von Aquin argumentiert, dass der Teufel eben deswegen seine irdischen Helfer - Hexen und Magier - braucht, um Materie bewegen und Schaden zufügen zu können. Der Teufel muss im Inneren des Menschen wirken und ihn durch Illusionen verblenden, um ihn dazu zu motivieren, wozu er ihn nicht physisch zwingen kann. Der Teufelspakt gehört zu einem der Mittel, mit denen der Teufel die Menschen anlockt. Vgl. z. B. Augustinus, Aurelius: Vom Gottesstaat, Bd. 1, 2. Hrsg. von Carl ANDRESEN u. a., Zürich 1978, hier Bd. 2, 21, 6, S. 686 f. Thomas von Aquin: Quaestiones Disputatae. Vom Übel, Bd. 12/Teilband 2. Hrsg. von Rolf SCHÖNBERGER, Hamburg 2010. Kramer, Heinrich: Der Hexenhammer. Hrsg. von Günter JEROUSCHEK/Wolfgang BEHRINGER, München 2000. Vgl. dazu FlaSCH, Kurt: Der Teufel und seine Engel. Die neue Biographie, München 2015, S. 97, 110f., 114. OTTO, BerndChristian: Magie. Rezeptions- und diskursgeschichtliche Analysen von der Antike bis zur Neuzeit, Berlin, New York 2011, S. 317-318. 
er Tag vnd Nacht nach / name an sich Adlers Fluegel / wolte alle Gruend am Himmel vnd Erden erforschen [. . .]. ${ }^{24}$ Die Reihung der Verben - lieben, trachten, nehmen, erforschen wollen usw. - deutet darauf hin, dass Faust sich aktiv engagiert, um sich dem Teufel zu nähern.

In der Szene der ersten Beschwörung führt der Teufel im Wald zunächst ein langwieriges Spektakel voller beunruhigender Bilder und Lärm auf, ohne in menschenähnlicher Gestalt aufzutreten. Faust ist erschrocken, will sogar fliehen, aber sein starkes Fuernemmen, den Teufel $\mathrm{zu}$ beschwören, überwindet seine Angst. Nachdem Faust zweimal Mut gefasst und viermal neu beschworen hat, erscheint endlich der Teufel in Gestalt eines grauwen Muenchs / kam mit Fausto zusprach / fragte / was er begerte. ${ }^{25}$ Erst jetzt, nach langer Verzögerung kann Faust sein Vorhaben durchsetzen und zu einer effektiven Kommunikation mit dem Teuflischen kommen.

Auf ähnliche Weise treibt Faust in den folgenden Szenen die Verhandlung um die Paktbedingungen voran, während Mephostophiles sie mit der Begründung verzögern will, dass nicht er, sondern sein Fürst das endgültige Bestimmungsrecht habe. Nachdem beide Seiten die Paktbedingungen abgesprochen haben, besonders nachdem Mephostophiles Faust versprochen hat, so er solche Puncten halten wuerde / soll er alles das haben / was sein Hertz belueste vnd begerte, ${ }^{26}$ so dass ihm ein Raum der Willensfreiheit versprochen worden ist, sticht Faust sich in die Hand, um den Pakt mit seinem Blut formell zu beglaubigen. Da erscheint in dieser Hand die blutige Schrift: O Homo fuge / id est / O Mensch fluehe vor jhme vnd thue recht, also eine übernatürliche Warnung vor dem bevorstehenden Teufelspakt und womöglich die einzige Erscheinung der heiligen Kraft im ganzen Faustbuch. ${ }^{27}$ Aber auß grosser seiner Verwegung und Vermessenheit lässt Faust sich nicht durch die Warnung davon abbringen, wonach er sich seit langem gesehnt hat. Die Intensität von Fausts Willen zum Teufelsbündnis spitzt sich in der Formulierung des Pakts zu:

Ich Johannes Faustus D. bekenne mit meiner eygen Handt offentlich / zu einer Bestettigung / vnnd in Krafft diß Brieffs / Nach dem ich mir fuergenommen die Elementa zu speculieren / vnd aber auß den Gaaben / so mir von oben herab bescheret / vnd gnedig mitgetheilt worden / solche Geschickligkeit in meinem Kopff nicht befinde / vnnd solches

24 Historia, S. 14-15. Eine rätselhafte Tatsache: Das Wort ,Datum‘ bedeutet auf Frühneuhochdeutsch ,Streben', auf Latein aber ,Gabe‘. Die gegenläufigen Lesarten deuten jeweils auf Willensfreiheit oder Determinismus hin.

25 Historia, S. 15-17; vgl. zur Bedeutsamkeit dieses teuflischen Erscheinungsbildes zudem den Beitrag von Daniela FuHRMAnN in diesem Band.

26 Historia, S. 21.

27 Historia, S. 22. 
von den Menschen nicht erlehrnen mag / So hab ich gegenwertigem gesandtem Geist / der sich Mephostophiles nennet / ein Diener des Hellischen Printzen in Orient / mich vntergeben / auch denselbigen / mich solches zuberichten vnd zu lehren / mir erwehlet / der sich auch gegen mir versprochen / in allem vnderthenig vnnd gehorsam zuseyn. [. . . $]^{28}$

Er begründet damit seine Motivation zum Teufelspakt plausibel: Er sucht nach etwas, das er allein mit den von Gott gegebenen Gaben nicht erreichen kann. Die Reihung der fleischlichen und seelischen Teile Fausts - eigner Hand, eygen Blut, meines Sinns, Kopffs, Gedancken vnnd Willen - soll die Authentizität und die Stärke seines Willens bezeugen und die Verbindlichkeit des Pakts bestätigen. Bis zu diesem Zeitpunkt sieht es so aus, als ob Faust derjenige ist, der aktiv handelt und das Geschehen vorantreibt.

\subsection{Heilige oder teuflische Ehe: Der erste Konflikt}

Sobald der Pakt unterzeichnet worden ist, fängt Mephostophiles an, sehr aktiv auf Faust einzuwirken. Dank Mephostophiles' diebischer Dienstleistungen erhält Faust köstliches Essen, Trinken und Kleidung sowie seine Bestallung. ${ }^{29}$ Aber sehr bald darauf enden diese ,Flitterwochen' mit einem schrecklichen Erlebnis der echten - eventuell aber auch nur scheinbaren - teuflischen Gewalt. Wegen seiner Aphrodisia will Faust sich verheiraten und weiben. Die Ehe, so erfährt er jedoch von Mephostophiles, sei ein Werck deß Hoechsten und dem Teufel und dem Pakt zuwider. Mephostophiles bedroht Faust, dass er ihn zerstückeln wird, wenn er sich verheiratet. Faust - paradoxerweise wider Gott und wider den Teufel zugleich - gedacht jhm hin vnnd wider nach / wie aller Gottlosen Hertzen nichts guts gruenden koennen / vnd der Teuffel dieselbigen leytet vnd fuehret, und beschließt am Ende, dass er sich doch verheiraten wolle, es folge darauß gleich was es woelle. Sofort darauf erscheint der Höllenfürst Satan leibhaftig vor Faust, führt sich so auf, als ob er ihn töten und seine Wohnung niederbrennen wolle, und drängt ihn dazu zu gestehen, dass er sich an den Pakt zwischen ihnen nicht gehalten und nun um Verzeihung zu bitten habe. Danach verschwindet Satan, und Mephostophiles tritt wieder hervor, verspricht Faust, dass er ihm alle Tag vnd Nacht ein Weib zu Bett fuehren wolle, welches auch immer er begehre, solange er ein schlechtes Leben führe. So sucht Faust immer weitere Befriedigung. ${ }^{30}$ Fausts Willensstärke wird hier erneut greifbar, aber

28 Historia, S. 22-23.

29 Historia, S. 24-27.

30 Historia, S. 27-29. 
diesmal unterdrückt der äußere Einfluss - anders als die Erscheinung der blutigen Schrift Homo fuge - seinen Willen. Faust tut jetzt willig, was er eigentlich auch tun muss. Durch diese Szenen wird klar, dass der Teufel es sehr gut versteht, mit Zuckerbrot und Peitsche den menschlichen Willen zu beeinflussen. ${ }^{31}$

\subsection{Die Disputationen: Fausts Rückzug}

Teils schockiert, teils mitten in der Teufflischen Ehe und am Teuflischen besonders interessiert, stellt Faust Mephostophiles in den folgenden Kapiteln dämonologische Fragen jeweils über die Natur des Teufels (Kap. 11), den Höllensturz Lucifers (Kap. 11 und 14), die Hölle (Kap. 12 und 16) und die Politik des Teufels bzw. die Art und Weise, wie der Teufel sein Regiment bildet (Kap. 13) und wie er seine Macht ausübt (Kap. 15). Diese Fragen betreffen das Wissen der Dämonologie sowie das Wissen über die Transzendenz. Gerade durch sie nähert sich Faust seinem tatsächlichen Belang an, nämlich der transzendenten Frage, ob Rettung (überhaupt) möglich ist. Einerseits will er gewisse transzendente Erkenntnisse von Mephostophiles erzwingen, andererseits will er ihm sein Vertrauen auch nicht ohne Weiteres schenken, weil er ein Speculierer und ihm somit bewusst ist, dass der Teufel nach der theologischen wie dämonologischen Lehre ein Luegen Geist ist. ${ }^{32}$ Daher will er Mephostophiles mit den Paktartikeln zügeln, so dass er das jenig / so er [i. e. Faust] von jm forschen wuerd / nicht verhalten und auff alle Interrogatorien nichts vnwarhafftigs respondiern soll. ${ }^{33}$ Auch die Wiederholung ähnlicher Fragen ist womöglich ein Ausdruck seines Misstrauens.

Mephostophiles, der nun zum Vermittler des transzendenten Wissens wird, nutzt die Disputationen, um Faust zu beeinflussen. Wenn über transzendente Sachen spekuliert wird, ob deterministisch oder indeterministisch, besteht Ungewissheit. Einerseits kritisiert Luther die Theorie der Willensfreiheit auch deswegen, weil man sich dabei nie sicher sein könne, wie viel Werk endgültig für die eigene Rettung ausreichend sei; ${ }^{34}$ andererseits ist der Nachteil der deterministischen Sichtweise ebenso unverkennbar: Man kann nie sicher sein, ob man eigentlich zur Rettung oder Verdammung prädestiniert ist. Aber die Disputation kann auch dem Teufel eine heikle Situation bereiten. In der mittelalterlichen

31 Vgl. KönNEKER, Faust-Konzeptionen, S. 185/186 (Anm. 4); MÜLLER, Der andere Faust, S. 580

f. (Anm. 10).

32 Vgl. Historia, S. 8, 11, 84, 116.

33 Historia, S. 18.

34 Luther, De servo arbitrio, S. 648-651. 
Legende ist es möglich, durch Auseinandersetzungen mit dem Teufel zur wahren transzendenten Erkenntnis zu gelangen, die den Teufelsbündler schließlich zum Heil führt. ${ }^{35}$ Mephostophiles muss seinerseits verhindern, dass sich Faust durch die wahre transzendente Erkenntnis von ihm abwendet und zu Gott zurückkehrt. Also entfaltet sich das Spannungsfeld zwischen Faust und Mephostophiles in vollem Umfang.

Zunächst reagiert Mephostophiles auf Fausts Fragen entweder mit ausweichenden oder verwirrenden Antworten. Von der Frage um den Höllensturz Lucifers z. B. ist Mephostophiles abgekommen, stattdessen spricht er jetzt nur von dem glänzenden Engelszustand Lucifers vor dem Höllensturz. ${ }^{36}$ Auf die Frage um die Substanz / Ort vnnd Erschaffung der Hellen sucht Mephostophiles dann Zuflucht im Agnostizismus. ${ }^{37}$ Damit ist Faust alles andere als zufrieden, er konfrontiert Mephostophiles erneut mit ähnlichen Fragen. Im Kapitel 14 kann Mephostophiles die Frage, Jn was gestalt sein Herr im Himmel geziert gewest / vnd darinnen gewohnet, nicht sofort beantworten und bittet um eine Bedenkzeit von drei Tagen. Fristgemäß kommt er zurück und verschweigt nicht mehr, dass Lucifer wegen seines Stolzes vom Himmel in die Hölle verstoßen wurde. Diese Antwort macht Faust mit ihrer theologischen Exemplarität und Tiefe geistig wie emotional betroffen. Er identifiziert sich mit Lucifer und bekommt Angst vor seiner eigenen Bestrafung: [M]ein vbermuehtig Fleisch vnd Blut hat mich / an Leib vnd Seel / in Verdammlicheit gebracht [. . .]. ${ }^{38}$ In Fausts Gedanken lassen sich beide hier interessierenden Überzeugungen ablesen: Zum einen die Willensfreiheit, die seinen Stolz und Übermut verantwortlich sieht für seine Sünden und die daraus resultierende Verdammnis; zum anderen aber auch eine deterministische Überzeugung, welche die Ursache in seiner Natur, seinem Fleisch vnd Blut sieht.

Die Antworten von Mephostophiles werden in Kapitel 15 und 16 immer länger und bereiten Faust immer größere geistige wie emotionale Unruhe. Von Kapitel 15 an spricht Faust von seiner Gefangenschaft oder Besessenheit vom Teufel. ${ }^{39}$ Auf die Frage über die Regierung, Raht, Gewalt, Angriff, Versuchungen

35 Vgl. die Erzählung von Cyprianus. Da gesteht der Teufel Cyprianus, dem Teufelsbündler, nach einer Folge von Misserfolgen ehrlich ein, dass er Gott unterlegen sei. Im nächsten Augenblick schwört Cyprianus dem Teufel und seinen Dämonen ab. Der einstige Zauberer Cyprianus wird schließlich ein Heiliger. In: De Voragine, Legenda, S. 1854-1863.

36 Historia, S. 29/30.

37 Historia, S. 30.

38 Historia, S. 32/33.

39 Interessant ist die Tatsache, dass hier nicht Mephostophiles, sondern nur Faust selbst davon spricht, dass der Teufel ihn ,besessen` und ,gefangen“ habe (abgesehen von den Erzähler-Kommentaren). Vgl. Historia, S. 35, 115. 
und Tyranney geht Mephostophiles diesmal tiefer ein, obwohl er zuerst seinen Widerwillen darüber geäußert hat, diese Frage zu beantworten. Erinnert man die alte Paktlegende, so ist an diesem Punkt vorstellbar, dass die Grenze des Teufels sich bald offenbaren und der Teufelsbündler die Unzulänglichkeit des Teufels erfahren wird. Aber unmittelbar darauf bewegt sich die Narration in die Gegenrichtung. Mephostophiles überschreitet selbst die Grenze, erzählt allerlei Übeltaten, die die Teufel seit dem Sündenfall des Menschen bis heute begangen haben, und berichtet, dass sie den Menschen vom Glauben abbringen und zur Sünde reizen, indem sie das Herz des Menschen besitzen. Er beendet seine Antwort mit der Behauptung, dass Faust das bei sich selbst auch beobachten könne. Faust erstaunt das sehr: So hastu mich auch Besessen? Lieber sage mir die Warheit? Darauf erklärt Mephostophiles detailliert, wie er Einfluss auf Faust ausgeübt und Schritt für Schritt Besitz von ihm ergriffen hat:

Ja / warumb nicht? Denn so bald wir dein Hertz besahen / mit was Gedancken du vmbgiengest / vnd wie du niemands sonsten zu deinem solchen Fuernemmen vnnd Werck koendtest brauchen vnd haben / dann den Teuffel / Sihe so machten wir deine Gedancken vnd Nachforschen noch frecher vnd kecker / auch so begierlich / daß du Tag vnnd Nacht nicht Ruhe hettest / Sondern alle dein Tichten vnnd Trachten dahin stunde / wie du die Zaeuberey zu wegen bringen moechtest / Auch da du vns Beschwurest / machten wir dich so Frech vnd Verwegen / daß du dich ehe den Teuffel hettest hinfuehren lassen / ehe du von deinem Werck werest abgestanden. Hernach behertzigten wir dich noch mehr / biß wir dir ins Hertz pflantzten / daß du von deinem Fuernemmen nicht mochtest abstehen / wie du einen Geist moechtest zu wegen bringen. Letzlich brachten wir dich dahin / daß du dich mit Leib vnd Seel vns ergabest / das kanstu alles / Herr Fauste / bey dir abnemmen. ${ }^{40}$

Bisher stützte die Narration die Lesart, dass Faust derjenige ist, der das Teufelsbündnis aktiv erwirkt und auch die Interaktion darin bestimmt hat. Nach Mephostophiles aber hat der Teufel Fausts Gedanken und Begierde schon längst beeinflusst, bevor dieser ihn erstmals beschwor. Der Teufel vermag, das menschliche Herz zu besehen, zu behertzigen und die Begierde darein zu pflantzen; all dessen kann der betroffene Mensch sich nicht bewusst werden. So gesehen erweisen sich viele Tätigkeiten des Teufels plötzlich als zweckmäßig, auch wenn er scheinbar passiv handelt. Er lässt sich lange beschwören, um Fausts Willen zu erproben; er verweigert auf die eine oder andere Weise, die von Faust geforderten Auskünfte sofort zu geben, um seine Neugier anzustacheln. Es liegt nahe, dass der Teufel noch viel mehr getan hat, um Faust an sich zu ziehen und sein teuflisches Interesse zu stärken, und zwar viel mehr, als die Menschen - sowohl Faust als auch der Erzähler und der Leser - erkennen können. Von diesem Punkt an scheint die

40 Historia, S. 35. 
Narration eine sehr eingeschränkte zu sein, denn sie muss meistens einen menschlichen Gesichtspunkt einnehmen und aus diesem hinausblicken, ohne den teuflischen Gesichtspunkt, der für die Narration konstruktiv auch unentbehrlich ist, hinreichend einzubeziehen. Faust scheint die Äußerung von Mephostophiles zu glauben, aber seine Vorstellung von der Willensfreiheit ist noch nicht ganz enttäuscht. Er spricht auch von seiner Teilnahme daran: Es ist war / sagt D. Faustus / nun kan ich jm nimmermehr thun / Auch habe ich mich selbst gefangen. ${ }^{41}$ Faust bereut, was er getan hat, wünscht, dass er anders gehandelt hätte, und bezweifelt, ob er irgendwann in der Vergangenheit sein Glück mit seiner Missetat schon verscherzt habe. Mephostophiles nährt seine Verwirrung mit der unklaren Aussage: Da sihe du zu. Das macht Faust trawrig und er geht fort.

Im Kapitel 16 stellt Faust Mephostophiles wiederum Fragen über die Hölle. Ganz deutlich drückt Faust seinen persönlichen, zentralen Belang aus: ob der Verdampte wider zur Hulde Gottes kommen koenne / vnd von der Hellen erloeset moechte werden ${ }^{42}$ Ähnlich wie früher will Mephostophiles Fausts Fragen ablehnen. Faust entgegnet: So wil ichs wissen / oder wil nicht leben / du must mirs sagen. ${ }^{43}$ Mephostophiles beginnt, auf die Fragen sehr wortreich, ja bis zum Überdruss einzugehen, und beschreibt die Pein und Hoffnungslosigkeit in der Hölle mit einer Vielzahl von Bildern. Er beendet seine langwierige Rede mit einer neuen Verweigerung: ich bin dir solches zu sagen nit schueldig, die offenkundig dem Paktartikel, dass er Faust gehorchen und gehorsam sein soll, widerspricht. Faust geht abermals gantz Melancholisch vom Geist hinweg / wardt gar Verwirret vnd Zweiffelhafftig / gedacht jetzt da / dann dorthin. Als er seine Gedanken schweifen lässt und an Gottes Wort denkt, lenkt Mephostophiles ihn sofort von diesen Gedanken ab, indem er sich in die Gestalt einer schönen Frau verwandelt und mit Faust all Vnzucht treibt.

Obwohl Mephostophiles die Auskunft auf alle Fragen verweigert, will Faust im Kapitel 17 noch ein ,Gedankenexperiment' von ganz zentraler Bedeutung mit Mephostophiles machen. Er fordert Mephostophiles auf, sich in seine Rolle hineinzuversetzen, und fragt ihn, was er dann tun wollte, wenn er ein Mensch wäre. Dieser laechelte und lehrt Faust mit einer synergistischen Denkweise, dass er als Mensch sein Bestes tun müsste, um sich Gott gefällig zu machen. Faust ist sich bewusst, dass er solches nicht getan habe, und gerät eben durch die synergistische Idee tiefer in Verzweiflung. Er fragt Mephostophiles weiter, ob er ein Mensch sein wollte. Dieser entgegnet nun mit einem Seufzer, zeigt

41 Historia, S. 35.

42 Historia, S. 36.

43 Historia, S. 37. Eigentlich kann man dem Teufel nicht mit Selbstmord drohen, aber auf mysteriöse Weise wirkt die Drohung. Das bietet auch Ansätze zur Spekulation. 
sich reuig über eigene Sünde, spielt eine Figur, die Missetaten begangen habe und jetzt bereue, aber doch keine Hoffnung habe. Darauf scheint Faust sich selbst allzu leicht in diese vom Teufel konzipierte Figur hineinversetzt zu haben: So were es mit mir auch noch frueh gnug / wann ich mich besserte. Er glaubt nun, dass es für ihn schon zu spat sei zu bereuen. Dies alles ist so qualvoll, dass er keine Antwort mehr von Mephostophiles hören will: Laß mich zu frieden / sagt Doctor Faustus zum Geist. Antwort der Geist / So laß mich forthin auch zu frieden mit deinem Fragen. ${ }^{44}$

Faust stellt Mephostophiles darauf keine dämonologischen Fragen mehr, untersucht die Transzendenz aber weiterhin, indem er mit Mephostophiles' Hilfe Astronomie und Geographie empirisch studiert. Er [n]impt jm derwegen fuer / den Geist zu fragen / vnter einem glimpff / [ . . ] von deß Himmels Lauff / Zierd / vnnd desselben Vrsprung. ${ }^{45}$ Diese Herangehensweise, die Transzendenz durch die Empirie zu untersuchen, muss im prä-cartesianischen sechzehnten Jahrhundert so reizvoll wie umstritten gewesen sein. ${ }^{46}$ Die Ambiguität in der Aussage: [Faust] sahe wol gen Himmel / aber er kondte nichts ersehen, ${ }^{47}$ deutet schon darauf hin, dass das Heil und die Empirie nach der Sichtweise der Zeit ineinander verwoben zu sein erscheinen. Aber das Faustbuch lässt diese Herangehensweise an das Problem nicht zu. Faust erblickt auf dem Caucasus das Paradies aus der Ferne, das von dem Engel Cherub mit seinem Flammenschwert wie mit einer feurigen Mauer abgeschirmt wird. Mephostophiles spricht von der absoluten Unzugänglichkeit des Paradieses: [W]eder du / ich / noch kein Mensch kan dazu kommen. ${ }^{48}$ Das gilt als der entscheidende Bruch der Verbindung zwischen Trans-

\footnotetext{
44 Historia, S. 43.

45 Historia, S. 46.

46 Über den Wissensdiskurs im Faustbuch wird in der Forschung viel diskutiert. Vgl. z. B. MÜLLER, Jan-Dirk: „Curiositas“ und „erfarung“ der Welt im frühen deutschen Prosaroman. In: Literatur und Laienbildung im Spätmittelalter und in der Reformationszeit. Hrsg. von Ludger GrenzmanN/Karl StackMAnN, Stuttgart 1984, S. 252-271; MÜlLER, Jan-Dirk: Ausverkauf menschlichen Wissens. Zu den Faustbüchern des 16. Jahrhunderts. In: Literatur, Artes und Philosophie. Hrsg. von Walter HAUG/Burghart WACHINGER, Tübingen 1992, S. 163-194; RUBERG, Uwe: Zur narrativen Integration enzyklopädischer Texte am Beispiel des Faustbuchs von 1587. In: Enzyklopädien der frühen Neuzeit. Hrsg. von Franz M. EyBL u. a., Tübingen 1995, S. 64-80; Classen, Albrecht: Faustbuch and Wagnerbuch as Witnesses of Paradigm Shift. In: Daphnis 35 3/4 (2006), S. 515-535; GEROK-REITER, Annette: Tradition und Transformation. Polyphone Wissensfigurationen in der Historia. In: KulturPoetik, Bd. 11, 1 (2011), S. 1-20; EmING, Jutta: Body Imagery and Knowledge in Historia von D. Johann Fausten. In: Anthropological Reformations - Anthropology in the Era of Reformation. Hrsg. von Anne EuSTERSCHUlte/Hannah WäLZHOLZ, Göttingen 2015, S. 113-128.
}

47 Historia, S. 36.

48 Historia, S. 72. 
zendenz und Immanenz auf der intradiegetischen Ebene. Erst darauf folgt der in der Forschung häufig sogenannte ,Schwankteil‘ (etwa Kap. 33-59) mit seinem überwiegend profanen Charakter, in dem es so aussieht, dass Faust seinen Drang in die Transzendenz endlich aufgibt und die vom Teufel gezogene Grenze für sein Handeln nicht mehr zu überschreiten versucht.

\subsection{Die Zauberei-Geschichten: Harmonie zwischen Faust und Mephostophiles}

Die Beziehung zwischen Faust und Mephostophiles tritt nun in eine stabile Phase des weltlichen Lebens ein. Die erzählte Zeit dieser Phase deckt den größten Teil der festgeschriebenen Frist des Pakts von vierundzwanzig Jahren ab. Nicht viel wird über Fausts Kommunikation mit dem Teufel berichtet, denn hier steht seine Verfahrensweise - mit der neu erworbenen Zauberkunst - in und mit der Welt im Zentrum. Aber aus den Zauberstücken, die gemäß der Definition von Mensch und Teufel nur gemeinsam hervorgebracht werden müssen, lässt sich schließen, dass Faust und Mephostophiles in dieser Phase eng miteinander verbunden $\mathrm{zu}$ sein scheinen und harmonisch zusammengewirkt haben. Nachdem Faust z. B. der Gräfin von Anhalt frische Trauben, die wegen der Jahreszeit nicht vorhanden sind, innerhalb einer halben Stunde herbeigeschafft hat, erläutert er selbst, dass die Saisonfrüchte eigentlich von seinem Geist aus einem anderen Erdteil besorgt wurden. ${ }^{49}$ Die Auffassung, dass der Mensch keine Zauberei ohne den Teufel ausüben und der Teufel kein Ding aus dem Nichts schaffen kann, entspricht der traditionellen Dämonologie. ${ }^{50}$ Aber in manchen Szenen erscheint Faust so, als ob er selbst wie er im Paktartikel gefordert hat - auch ein Geist wäre, der ohne Beschwörung die menschlichen Sinne verblenden oder außer Kraft setzen, sich unsichtbar machen oder eine andere Gestalt annehmen kann. Er schafft z. B. das Trugbild einer Armee, um einen Ritter abzuschrecken (Kap. 35 und 56). Er frisst scheinbar eine Fuhre Heu (Kap. 36 und 40). Er macht zwölf sich prügelnde Studenten temporär

49 Historia, S. 89/90.

50 Vgl. Augustinus, Gottesstaat, Bd. 2 21, 6, S. 686f.; Cotta, John: The triall of witch-craft, shewing the trve and right methode of the discouery: with a confutation of erroneous wayes. London 1616, S. 34: „[. . . ] the Divell as a Spirit doth many things, which in respect of our nature are supernaturall, yet in respect of the power of Nature in universall, they are but naturall unto himselfe and other Spirits, who also are a kinde of creature contained within the generall nature of things created: Opposite therefore, contrary, against or above the generall power of Nature, hee can do nothing." Vgl. dazu ClARK, Stuart: Thinking with Demons. The Idea of Witchcraft in Early Modern Europe, Oxford 1997, S. 165; OтTо, Magie, S. 317/318, 324f. (Anm. 23); FlaSCH, Teufel, S. 194f. (Anm. 23). 
blind (Kap. 41) und bezaubert lärmende Bauern, daß allen Bauwren das Maul auff das aller weitest offen stunde (Kap. 42). ${ }^{51}$ In diesen Zauberei-Geschichten ist die unabhängige Teufelsfigur nicht mehr so präsent wie zuvor, die Wirkung des Teufels wird selten wörtlich genannt. ${ }^{52}$ In den hier beschriebenen Zauberpraktiken ist es für den Leser schwierig zu erkennen, wer - im Sinne der aristotelischen Physik - als Agens die Veränderung und die Bewegung verursacht, auch ist es schwer, die Grenze zwischen Mensch und Teufel zu ermitteln.

\subsection{Fausts zweite Verschreibung: Das Erlöschen seines Willens?}

Die Episode, in der ein Nachbar Faust zu bekehren versucht, erinnert an die alten Paktlegenden, in denen der Teufelsbündler mithilfe seiner Mitmenschen oder eines Heiligen bekehrt wird. ${ }^{53}$ Das Wort des Nachbarn wirkt auf Faust so, dass er Buße tun und dem Teufel den Pakt aufkündigen will. Darauf folgt aber nicht - wie in den Paktlegenden - das Eingreifen der heiligen Macht, sondern das der teuflischen. Der Höllenfürst Satan muss diesmal nicht mehr selbst hervorkommen. Nur Mephostophiles ist am Werk, um Faust von dieser Absicht abzuschrecken. Er greift Faust tätlich an und wirft ihm vor, dass sein frecher Mutwillen - in Frühneuhochdeutsch manchmal mit ,Stolz' austauschbar ${ }^{54}$ dem Bündnis zwischen ihnen zugrunde liegt, und dass er jetzt sein Versprechen gebrochen habe. Nachdem Mephostophiles ihn nochmals mit dem ,zu spät‘ desillusioniert und die Drohung, ihn zu zerstückeln, ausgesprochen hat, verschreibt sich Faust dem Teufel erneut mit seinem Blut wie aufgefordert:

Jch D. Faustus bekenne mit meiner eygen Handt vnd Blut / daß ich diß mein erst Jnstrument vnnd Verschreibung biß in die 17. jar / steiff vnd fest gehalten habe / Gott vnd allen Menschen feindt gewest / hiemit setz ich hindan Leib vnd Seel / vnd vbergib diß dem maechtigen Gott Lucifero / daß so auch das 7. jar nach Dato diß verloffen ist / er mit mir

51 Vgl. Eming, Body Imagery, S. 118f. (Anm. 46). Eming begründet, dass Fausts Begierde, die Grenzen zu transzendieren und Macht zu erlangen, sich durch die Groteske der Körperlichkeit manifestiert.

52 Vgl. RöcKe, Werner: Das verkehrte Fest. Soziale Normen und Karneval in der Literatur des Spätmittelalters. In: Neohelicon XVII (1990), S. 203-231, hier S. 225-227. RöcKE sieht im Faustbuch die karnevaleske Logik, Normen zu verkehren, Grenzen zu überschreiten und Gegensätze aufzuheben. Ich würde argumentieren, dass hier die Grenze zwischen dem Teufel und dem Teufelsbündler auch in einer karnevalesken Weise zum Teil abgeschafft wird.

53 Historia, S. 101-103. Für die alten Paktlegenden vgl. De Voragine: Legenda, S. 418-423, 1752-1755, 1854-1863 (Anm. 2).

54 Artikel ,stolz' (Maskulinum) in FWB-online (die Online-Version des Frühneuhochdeutschen Wörterbuches: http://fwb-online.de/go/stolz.s.0m_1573744929; Zugriff: 14. November 2019). 
zu schalten vnd zu walten habe. [. . . ] Hierauff versprich ich mich wider / daß ich keinen Menschen mehr / es seye mit vermahnen / lehren / abrichten / vnterweisen vnd draeuwungen / es sey im Wort Gottes / weltlichen oder Geistlichen Sachen / vnd sonderlich keinem Geistlichen Lehrer gehorchen / noch seiner Lehr nachkommen wil / Alles getrewlich vnd kraefftig zu halten / laut dieser meiner Verschreibung / welche ich zu mehrer bekraefftigung mit meinem eygen Blut geschrieben hab / Datum Wittenberg / etc. ${ }^{55}$

Vor der ersten Verschreibung hatte Faust selbstbewusst seine Forderungen Punkt für Punkt genannt und hartnäckig mit dem Teufel verhandelt. Im Vergleich dazu ist Faust hier nur noch der Wille verblieben, seine im Pakt festgeschriebene restliche Lebenszeit $\mathrm{zu}$ vertreiben. Zur Bekräftigung bleiben jetzt nur noch seine fleischliche Komponente, sein eygen Handt und eygen Blut, während die seelischen Zeugen in der ersten Verschreibung - sein Sinn, Kopff, Gedancken und Willen - ausbleiben. Bedeutet dies das vollständige Erlöschen seines Willens?

\subsection{Die Klagen: Fausts kurzlebiges Gewissen}

In der emotionalen wie geistigen Unruhe seines letzten Monats tritt eine seelische Instanz in Faust unerwartet signifikant hervor, die kulturhistorisch gesehen für die Reformationszeit zentral war, die aber im Faustbuch grundsätzlich noch keine Rolle gespielt hat: sein Gewissen. Luther schätzt den menschlichen Willen negativ ein, das Gewissen dagegen aber durchaus positiv, obwohl sich beide in der Hinsicht ähnlich sind, dass sie als innere geistige Instanzen die menschliche Handlung steuern. Der Unterschied zwischen ihnen liegt wohl in der Frage, ob die Richtung der Handlung fortgesetzt oder umgekehrt wird. Luther beschreibt selbst seine intellektuelle Verzweiflung gegenüber der Einsicht, dass der Mensch keine Willensfreiheit hat. Nur mit dem Gewissen konnte er diese Verzweiflung überwinden und seither entschieden dem Glauben anhängen. ${ }^{56}$ Daraus ergibt sich: Das Gewissen ist wohl die letzte Urteilsinstanz von Recht und Unrecht, die letzte geistige Burg des Menschen vor dem Eindringen der Verzweiflung. Fausts Gewissen erwacht im letzten Monat. Er ließ sich forthin selten oder gar nit sehen / wolte auch den Geist nit mehr bey jm sehen oder leyden. ${ }^{57}$ Er will allein in einer Klause leben und nur mit sich reden, klagt sich unter Tränen selbst an und zeichnet seine Klagen auf. ${ }^{58}$ Faust ist in sich nicht mehr einig, sondern er wird

55 Historia, S. 104.

56 Luther, De servo arbitrio, S. 486/487.

57 Historia, S. 113.

58 Über Fausts Subjektivität durch das Schreiben siehe MÜNKLER, Ambiguität, S. 313-316 (Anm. 18). 
in mehrere, separate geistige Instanzen zergliedert. Das Gewissen löst sich zuerst von ihm ab, beschuldigt sich wie die übrigen Instanzen eine nach der anderen:

Ach Fauste / du verwegenes vnnd nicht werdes Hertz [. . . ] / Ach Vernunfft vnd freyer Will / was zeihestu meine Glieder [. . . ] / Ach jhr Glieder / vnnd du noch gesunder Leib / Vernunfft vnd Seel / beklagen mich [. . . . $]^{59}$

Damit erreicht Faust eine Einsichtsfähigkeit, die in den alten Paktlegenden ein heilsames Element ist. ${ }^{60}$ Aber das bedeutet nicht, dass Faust schlussendlich doch bereut. Anders als Luthers Gewissen, das mit dem Glauben versehen ist, gerät sein Gewissen sowohl in eine deterministische Verwirrung hinsichtlich der Frage, ob er erwählt oder verflucht sei, als auch in die halb-deterministische Verzweiflung, dass er sein Glück wahrscheinlich schon unwiderruflich verspielt habe.

Ach jhr Glieder / vnnd du noch gesunder Leib / Vernunfft vnd Seel / beklagen mich / dann ich hette dir es zu geben oder zu nemmen gehabt / vnd mein Besserung mit dir befriedigt. Ach Lieb vnnd Haß / warumb seyd jr zugleich bey mir eingezogen / nach dem ich euwer Gesellschafft halb solche Pein erleiden muß / Ach Barmhertzigkeit vnd Rach / auß was vrsach habt jr mir solchen Lohn vnd Schmach vergoennet? O Grimmigkeit vnd Mitleyden / bin ich darvmb ein Mensch geschaffen / die Straff / so ich bereit sehe / von mir selbsten zu erdulden ${ }^{61}$

Der Teufel muss selbst dieses bereits verdorbene Gewissen völlig vernichten. Mephostophiles überflutet Faust mit einem Gemenge von spöttischen Sprichwörtern und theologisch scheinbar abgesicherten Predigten. Der Grund, warum man dem Teufel nicht vertrauen darf, so Mephostophiles, bestehe darin, dass er [i. e. der Teufel] GOttes Aff / auch ein Luegner vnnd Moerder ist. ${ }^{62}$ Alles, was er gesagt hat, wird damit fragwürdig. Nun gerät Faust in äußerste Ungewissheit. Es wäre ihm lieber, als ein Vieh ohne Seele geboren zu sein. In der dritten Klage beschuldigt Faust sich nicht mehr, sondern er denkt stets ,technisch“ über Möglichkeiten nach, die höllische Qual zu mildern oder zu vermeiden, was er selbst jedoch am Ende der Klage wiederum für unmöglich hält. Er redet

59 Historia, S. 113/114.

60 Vgl. z. B. die Erzählung vom Diener des Helladius, in der die Öffnung des geistigen Auges stufenweise beschrieben wird. Der heilige Basilius schloss den Sünder in ein Zimmer ein. Er besucht und ermutigt ihn dreimal, bevor er ihn schließlich exorziert. Beim ersten Besuch berichtet der Mann Basilius von gesehenen und gehörten Bedrohungen des Teufels, die er beim zweiten Besuch nur noch von Weitem hören kann, und beim dritten sieht er Basilius für ihn „im Geist [. . . ] kämpfen und den Teufel besiegen“. In: De Voragine: Legenda, S. 420-423.

61 Historia, S. 114.

62 Historia, S. 116. 
sich und seine Teile nicht mehr mit $D u$ oder $I h r$ an, sondern spricht stets nur Ich. Das deutet darauf hin, dass sein Gewissen, das in den zwei vorherigen Klagen noch als eine unabhängige Urteilsinstanz funktionierte, jetzt verschwunden ist. In seinem letzten Auftritt bietet Mephostophiles Faust an, der Teufel woelle dir [i. e. Faust] einen staehlin Leib vnnd Seel geben / vnd solt nicht [unter dem höllischen Feuer] leyden / wie andere Verdampte - was nicht anders als nach einem neuen Spott klingt. ${ }^{63}$ Mephostophiles' Werk ist vollbracht. Nun steht bloß noch aus, dass der geistig bereits gestorbene Faust auch körperlich getötet und zermalmt wird.

Fausts Willensfreiheit wird also immer mehr beschränkt. Am Anfang ist er der Agens, der willig und aktiv auf den Teufelspakt dringt, der Inbegriff seines Willens ist der Text des Pakts. Graduell stößt sein Wille auf die Grenze zur Notwendigkeit. Als Faust heiraten will, zwingt ihn der Teufel einerseits, dieses Vorhaben aufzugeben, andererseits gewährt er ihm sexuelle Befriedigung. Trotz dieses ersten Konflikts und des Schreckens der teuflischen Gewalt können Faust und der Teufel das Gleichgewicht ihrer Beziehung schnell wieder herstellen. Aber Faust versucht weiterhin hartnäckig herauszufinden, wie weit er seine Willensfreiheit auszudehnen vermag. In reibungsvollen Disputationen stellt Faust Mephostophiles wiederholt heikle Fragen. Die Ungewissheit, ob er zur Verdammung prädestiniert sei, ob er wegen eigener Sünde verdammt sei und ob es für ihn zur Reue schon zu spät sei, versetzt dem Willen Fausts einen tödlichen Stoß. Die Qual dieser Ungewissheit kann Faust nicht mehr aushalten, er zieht sich vor dem theologisch-philosophischen Spannungsfeld zwischen Willensfreiheit und Determinismus zurück, gibt das Streben auf, die Grenze seiner Freiheit auszuloten und seine Rechte in der Partnerschaft zu erweitern. Mit Fausts Nachgeben wird die Beziehung zwischen Faust und Mephostophiles für eine lange Dauer stabil und harmonisch. Im Schwankteil sind sie sich weitgehend einig und verschmelzen $\mathrm{zu}$ einem einzigen Agens. Aber diese Harmonie wird wiederum gebrochen, als Faust sich auf die Warnung eines Alten hin bekehren lassen will. Auf Eingreifen von Mephostophiles hin scheitert dieser Versuch augenblicklich. Eine zweite Verschreibung wird erstellt, um Fausts Treue gegenüber dem Teufel urkundlich zu bezeugen. Damit wird offenbart, dass Fausts Wille in der scheinbaren Harmonie schon langsam zurückgeht und mit der zweiten Verschreibung womöglich völlig verschwunden ist. Andererseits zeigt dieser vergebliche Versuch zumindest einen Ansatz einer positiven geistigen Unabhängigkeit Fausts von dem Teufel, die bisher im Faustbuch noch nicht vorgekommen ist. Diese Spur verstärkt sich in Fausts letztem Monat mit

63 Historia, S. 119. 
dem Erwachen seines Gewissens. Dieses aber ist ein bereits von Verzweiflung durchgedrungenes Gewissen und kann daher dem Teufel gegenüber nicht widerstandsfähig sein.

Damit komme ich zu meiner These zurück: Die Partnerschaft zwischen dem Teufel und seiner menschlichen Allianz ist ähnlich wie die Partnerschaft zwischen Gott und Christ des synergistischen Modells. Auf positive Weise verstanden ist der Teufelspakt eine Institution der gegenseitigen Ermächtigung der beiden beteiligten Parteien. Dies bedarf einer gegenseitigen Annäherung von Mensch und Teufel. Einerseits kann der Mensch ohne die teuflische ,Gnade keine Zauberkunst erlernen und ausüben, andererseits kann der Teufel ohne den menschlichen Willen, sich dem Teufel zu nähern, seinen Herrschaftsbereich nicht erweitern. Der Mensch muss am Anfang einen Willen mit freier Entscheidungskraft besitzen, frei zum Guten wie zum Bösen sein, so dass die endgültige Entscheidung zum Bösen umso wertvoller erscheint. Das Vorhandensein dieses Willens ist außerdem auch ein Vorteil für den Teufel, wie sich an Mephostophiles' Verhalten zeigt, denn dieser schreibt gern alle Sünden dem menschlichen Willen zu. Deswegen verfährt Mephostophiles immer vorsichtig mit Faust und zwingt ihn meist nicht mit Gewalt, obwohl der Teufel aufgrund seiner Überlegenheit gegenüber dem Menschen ihn leicht hätte zwingen können. Der Teufel motiviert. Er reizt und befriedigt Fausts Begierde, alles deswegen, damit Faust selbst willig tut, wozu der Teufel ihn bewegen will. Auf negative Weise verstanden muss der Wille mit freier Entscheidungskraft graduell schwinden, bis der Mensch sich dem Teufel vollkommen hingibt. Einerseits präsentiert er seine Gewalttätigkeit am Körper des Teufelsbündlers, andererseits stiftet er noch wirksamer in dessen Innerem emotionale und geistige Unruhe. Für einen hoch intelligenten und geschwinden Kopff wie denjenigen Fausts personalisiert Mephostophiles die Verführungsstrategie. Er fordert Faust zum intellektuellen Vexierspiel zwischen Determinismus und Willensfreiheit heraus, dessen Ausgang auch die realen Verhältnisse zwischen ihnen beeinflusst. Er gibt ihm widersprüchliche Hinweise, die theologisch und wissenschaftlich mal gut und mal schlecht fundiert sind, und führt ihn in einen Teufelskreis der Verzweiflung: Er sei entweder zur Verdammung prädestiniert oder habe zu viel Sünde begangen, um Vergebung erfahren zu können, oder es sei zu spät für ihn zu bereuen. ${ }^{64}$ Schließlich konfrontiert Mephostophiles ihn

64 Vgl. KÖNNEKER, Faust-Konzeptionen, S. 184-192 (Anm. 4). KöNNEKER schildert höchst plausibel einen Teufelskreis zwischen Hochmut und Verzweiflung: Einerseits stachelt der Teufel Fausts Begierde an, andererseits treibt er Faust immer wieder mit dem zu spat in die Verzweiflung, so dass Fausts Sünde sich zwischen beiden Formen der Leugnung von Gott kontinuierlich vermehrt. 
mit dem Lügner-Paradoxon (die Selbstbezeichnung des Teufels als Luegner), das die schon vielfach und vieldimensional gewordenen Paradoxa des Faustbuchs noch einmal verschachtelt. In diesem Labyrinth verliert Faust jede Orientierung, so dass er am Ende an nichts anderes denken kann als daran, in die Hölle zu gehen.

\title{
3 Eine teuflische Erzählweise
}

Das Faustbuch verfügt über eine merkwürdige Erzählsituation: Es gibt eine schwer erkennbare, nur angedeutete Ebene, die einen unschätzbaren Einfluss auf die erzählte Ebene hat - das ist die Ebene des Teufels. Diese Ebene wird ab und zu manifest, z. B. in dem Moment, wenn der Erzähler die innere Stimme des Teufels ausmalt:

\begin{abstract}
Da wirdt gewißlich der Teuffel in die Faust gelacht haben / vnd den Faustum den Hindern haben sehen lassen / vnd gedacht: Wolan / ich wil dir dein Hertz vnnd Muth erkuehlen / dich an das Affenbaencklin setzen / damit mir nicht allein dein Leib / sondern auch dein Seel zu Theil werde / vnd wirst eben der recht seyn / wohin ich [selbst] nit (wil) [werde] ich dich [als] meinen Botten senden / wie auch geschah / vnnd der Teuffel den Faustum wunderbarlich aefft vnnd zum Barren bracht. ${ }^{65}$
\end{abstract}

Auch die Selbstdarstellung des Teufels, der zufolge er Fausts Willen schon lange vor der ersten Beschwörung beeinflusst habe (Kap. 15), ist ein Anzeichen der Existenz einer anderen Ebene des Geschehens. Der Teufel deutet darauf hin, dass seine Ebene weit über die zeitliche und epistemologische Grenze der erzählten Ebene hinausreicht. ${ }^{66}$

In den alten Paktlegenden fehlt jegliche unerzählte Ebene des Geschehens. Ihre Narration ist linear, wird durch kein Mittel relativiert. Der Erzähler ist allwissend. Alle Handlungen können ohne Weiteres auf einen bestimmten Agens zurückgeführt werden. Theophilus selbst initiiert den Teufelspakt. Die Eltern von Cyprianus weihen ihn dem Teufel. Der Diener von Helladius geht zum Teufel, weil er die Tochter seines Herrn liebt und der Teufel diese Liebe entflammt hat. Ja, der Teufel kann das Innere des Menschen immer schon beeinflussen,

65 Historia, S. 16.

66 Das entspricht dem zeitgenössischen dämonologischen Bild, dass der Teufel in einem Bereich wirkt, in dem die Naturgesetze zwar gelten, den aber die Menschen (noch) nicht erkennen können. Der von Delrío benutzte Begriff ordo praeternaturalis würde diesen Bereich angemessener bezeichnen als die gängigeren Kategorien von ,Natur‘ und ,Übernatur‘. Delrío, Martín Antonio: Disquisitionum magicarum libri sex, Lugduni 1608, S. 25. 
ohne von der betroffenen Figur erkannt zu werden, aber der Erzähler macht dies dem Leser bekannt ohne jegliche Unschärfe. Die Narration des Faustbuchs dagegen wird durch unzählige Elemente relativiert: unzuverlässige Erzählinstanzen - der Erzähler widerspricht sich, der Teufel ist betrügerisch -, subversive Selbstauslegungen, doppelte Geschehensebenen und Paradoxa aller Arten.

In dieser Lage kann der Leser die Frage der Zurechenbarkeit der Sünde nicht mehr beantworten. Es ist nicht mehr zu unterscheiden, ob zuerst der Teufel zu Faust oder Faust zum Teufel gekommen ist, denn zwischen ihnen ist eine synergistische Wechselwirkung zu beobachten. Selbst wenn man Mephostophiles’ Auslegung Vertrauen schenkt, dass Faust es war, der an erster Stelle den Gedancken und Fuernemmen zum Teuflischen hatte, kann Faust ohne den Beistand des Teufels sowieso nichts ausrichten (vgl. Kap. 15). Darüber hinaus wird der Zusammenhang zwischen Sünde und Strafe im Lauf der Narration auch untergraben. Der Leser erwartet, je näher Fausts Ende ist, desto schwerer ist seine Sünde. Aber die Tatsache ist: Je näher Fausts Ende ist, desto schwächer ist sein Wille, der negativ konzipiert ist und negativ empfunden wird. So muss die Frage der Zurechenbarkeit der Sünde entweder auf ein Paradoxon oder auf die unergründliche Transzendenz laufen. Damit wird der Leser selbst auch zu derselben Position gezwungen, zu der Faust vom Teufel gezwungen wurde.

Eine weitere Gefahr, die in dieser Narration verborgen ist, ist die Entfesselung der Immanenz von der Transzendenz. Selbst ein Vertreter der deterministischen Sichtweise müsste anerkennen, dass im Faustbuch der Determinismus weder durch die Unausweichlichkeit der höchsten göttlichen Kraft - wie etwa durch einen Deus ex machina - noch durch die schlichte Kausalität der Materie konzipiert wird. Jedes Geschehen scheint vielmehr zugleich sowohl die Folge des Zusammenspielens der Willen verschiedener Agenzien als auch die Realisierung der Prädestination zu sein. So eine Überlagerung ist bei den alten Paktlegenden kein Problem. In ihnen haben die intra- und extradiegetischen Autoritäten noch solide Kontrolle über die Narration, da das Göttliche und Menschliche ihre klar definierten Rollen haben und auf derselben Ebene zusammenwirken. Im Faustbuch werden das Transzendente und das Immanente auf verschiedenen Geschehensebenen angeordnet. Dabei nimmt der Leser die Möglichkeit der Agenzien und Gottes Abwesenheit wahr, und er muss sich zugleich Gottes Prädestination und Gottes Allpräsenz vorstellen. Die Teufelsfigur, die aus der übernatürlichen bzw. ,präternatürlichen' Ebene in die natürliche Ebene hineingreift, ist der einzige, aber brüchige Anknüpfungspunkt der zwei Ebenen. $^{67}$

67 Über das Lexem ,präternatürlich‘ siehe: Delrío, Disquisitionum . . ., S. 25 (Anm. 66). 
Eine Ähnlichkeit dieser Narration mit der Dämonologie besteht darin, dass beide alle menschlichen Sinneswahrnehmungen nur als Schein des Movens einer höheren und schwer erkennbaren Existenzordnung betrachten. In der Frühen Neuzeit bedrohen aber die Bemühung, zwischen dem Natürlichen und dem Übernatürlichen zu unterscheiden, und die sich herausbildende neue wissenschaftliche Methode, sich nur auf das Natürliche oder second causes zu fokussieren, die Weltanschauung der Dämonologie. ${ }^{68}$ Sie erlebt im siebzehnten Jahrhundert folgerichtig einen allmählichen Bedeutungsverlust in der europäischen intellektuellen Landschaft. Die allmähliche Wende bezeugt das zeitgenössische Faustbuch. Noch in ihrer Hochkonjunktur verheißt das Faustbuch vielleicht schon die langsame Entfesselung der Immanenz von der Transzendenz in den kommenden Jahrhunderten, welches das Faustbuch in das großartige Bild fasst, dass Faust und Mephostophiles das Paradies, das vom Engel mit einer feurigen Mauer verteidigt wird, aus der Ferne erblicken und erkennen, dass keiner dorthin gelangen kann. ${ }^{69}$

68 ,Second causes“ auf Francis Bacon besagen: „For certain it is that God worketh nothing in nature but by second causes“. Bacon, Francis: The Advancement of Learning. Hrsg. von G. W. KiTchin, London 1962, S. 7/8.

69 Ich möchte Jutta Eming, Daniela Fuhrmann und Lorenz Gehrke für ihre Korrekturen und Vorschläge danken. 
